\title{
Investigation on the Thermal Fatigue Life Evaluation Method of Railway Brake Disc with New Material
}

\author{
Guangxue YANG, Yue YANG
}

\begin{abstract}
In this paper, the thermal fatigue life evaluation method of brake disc of high-speed train with new materials was proposed based on the experimental study and the finite element computation. Moreover, the aluminium alloy of SiCp/A356 composite was used to verify this method. The thermo-elasto-plastic constitutive model of SiCp I A356 composites was established, and the fatigue life curve of material at the initial stage of crack was established based on the thermal fatigue experiment. Based on the singular element method of finite element method, the crack propagation law of cracked fatigue specimens under thermal load is analysed, and the crack propagation curve, which can be used to predict the fatigue life of crack propagation under thermal load, is established. The results obtained in this paper agreed well with the results proposed in the related literature.
\end{abstract}

Keywords: brake disc; fatigue crack propagation; finite element analysis; singular element method; thermal fatigue life experiment

\section{INTRODUCTION}

As the most effective safety braking, the disc braking has been widely used in high-speed train. The lightweight of brake disc is helpful for the improvement of dynamics of bogie quality and the reducing of traction energy consumption. Under the braking condition, the braking disc can generate lots of heat due to the friction. Also, the heat distribution in the brake disc is uneven, which causes the thermal stress response of brake disc, and the ever-changing thermal stress is the driving force of crack generation. As for the thermal fatigue problem, the famous Manson-Coffin formula was proposed in 1953 to establish the relationship between the thermal strain and the fatigue life [1]. The new brake disc of high-speed train does not crack, and the fatigue crack such as the thermal crack can appear after many times of braking. However, the fatigue cracks will not invalidate the brake disc unless the crack grows to the critical length. Therefore, the fatigue life of brake disc can be divided into the crack initiation life and the crack propagation life. The Manson-Coffin formula is mainly used to predict the crack initiation life, and the crack propagation life is predicted by the fracture mechanics method.

During the braking process, some basic parameters of material can change with the temperature, so the experiment is a very important way to obtain the constitutive model and the fatigue properties of material with temperature. Li et al. [2] obtained the fatigue stress-strain curve of Cr-Mo-V low alloy steel by means of the tensile experiment and the fatigue experiment under the different temperatures ranging from the room temperature to $600{ }^{\circ} \mathrm{C}$. Additionally, the low cyclic fatigue characteristics of $\mathrm{Cr}-\mathrm{Mo}-\mathrm{V}$ low alloy steel were analysed. The results of the crack fracture analysis showed that the fatigue crack initially generated on the surface of brake disc. Although the working conditions of experiment are close to the actual working conditions of brake discs, the good monitoring means were absent. In general, only the surface temperatures were monitored, but the data of thermal fatigue damages could not be obtained.

The finite element method can well obtain the stressstrain response of the concerned regions of brake disc during the braking process, to obtain the thermal fatigue damages of materials. Zhou et al. [3] analysed the transient temperature and thermal stress distributions of brake disc under different working conditions by means of the thermalelastic-plastic finite element method. The calculated results were in agreement with the experimental results. As for the simulation of the crack propagation, the method of preset crack was considered, and $\mathrm{Wu}$ et al. [4] established a prediction model of the crack propagation of brake disc by the novel extended finite element method and the virtualnode polygonal finite element method. The predicted maximum braking temperature and the crack shape agreed well with the experimental results. Therefore, the finite element method was an effective means to obtain the thermal stress of brake disc.

This paper presents a method to evaluate the thermal fatigue life of brake disc of high-speed train based on the experimental method and the finite element simulation method. Moreover, the aluminium alloy of SiCp/A356 composite is applied to investigate this method.

\section{THE EVALUATION METHOD OF THE THERMAL FATIGUE LIFE OF BRAKE DISC}

The fatigue life of brake disc consists of the crack initiation life and the crack propagation life:

$N_{f}=N_{i}+N_{p}$

where $N_{i}$ is the crack initiation life; $N_{p}$ is the crack propagation life.

\subsection{The Analysis Method of the Crack Initiation Life}

The prediction of the crack initiation life is applicable to the strain fatigue life model attributed to the local deformation of brake disc during the braking process. Manson-Coffin formula [5] was widely used in the lowcycle fatigue life prediction of engineering structure:

$$
\frac{\Delta \varepsilon}{2}=\frac{\Delta \varepsilon_{e}}{2}+\frac{\Delta \varepsilon_{p}}{2}=\frac{\sigma_{f}^{\prime}}{E}\left(2 N_{f}\right)^{b}+\varepsilon_{f}^{\prime}\left(2 N_{f}\right)^{c}
$$


where $\sigma_{f}^{\prime}$ is the fatigue strength factor; $b$ is the fatigue strength index; $\varepsilon_{f}^{\prime}$ is the fatigue ductility factor; $c$ is the fatigue ductility index, and $E$ is the elastic modulus.

In this paper, the elastic term and the plastic term are considered separately due to the effect of the average stress:

$$
\begin{aligned}
\frac{\Delta \varepsilon_{e}}{2} & =\frac{\sigma_{f}^{\prime}-\sigma_{m}}{E}\left(2 N_{e f}\right)^{b} \\
\frac{\Delta \varepsilon_{p}}{2} & =\varepsilon_{f}^{\prime}\left(2 N_{p f}\right)^{c}
\end{aligned}
$$

where the parameters are the same as in Eq. (2).

The relationship between the elastic strain control life $\left(N_{e f}\right)$, the plastic strain control life $\left(N_{p f}\right)$, and the total life $\left(N_{f}\right)$ is shown as follows:

$$
\frac{1}{N_{f}}=\frac{1}{N_{e f}}+\frac{1}{N_{p f}}
$$

The Eq. (3) and the Eq. (4) are substituted into the Eq. (5), which is the prediction model of the thermal fatigue crack initiation life.

Obviously, the key to predict the fatigue life by using the strain fatigue life model is to obtain the constant stressstrain curve of material, which can generally be obtained by means of experiment.

\subsection{The Analysis of the Crack Propagation Life}

As the thermal crack and other fatigue cracks appeared on the brake disc, the Paris formula could be used to express the crack propagation life according to the fracture mechanics theory [6]:

$$
N_{p}=\int_{a_{i}}^{a_{c}} \frac{1}{\left(\frac{\mathrm{d} a}{\mathrm{~d} N}\right)} \mathrm{d} a=\int_{a_{i}}^{a_{c}} \frac{\mathrm{d} a}{C(\Delta K)^{m}}
$$

where $a_{i}$ is the initial crack depth; $a_{c}$ is the critical crack depth; $\mathrm{d} a / \mathrm{d} N$ is the crack growth rate, and $\Delta K$ is the range of the stress intensity factor.

The stress intensity factor $(K)$ was an important index, which reflected the stress field and the strain field of the crack tip and was an important parameter to estimate the crack propagation life [7]. Therefore, it was necessary to determine the relationship between the crack propagation rate $(\mathrm{d} a / \mathrm{d} N)$ and the stress intensity factor $(K)$ in the thermal cycle.

According to fracture mechanics theory, in the crack line $(\theta=0)$ :

$$
\sigma_{x}=\sigma_{y}=\frac{K_{I}}{\sqrt{2 \pi r}}, \tau_{x y}=0
$$

On account of $\tau_{x y}=\tau_{y z}=\tau_{z x}=0$, the main stress at any point of crack line is calculated as follows:
$\sigma_{1}=\sigma_{2}=\frac{K_{I}}{\sqrt{2 \pi r}}, \sigma_{3}= \begin{cases}0 & \text { Plane stress } \\ \frac{2 \nu K_{I}}{\sqrt{2 \pi r}} & \text { Plane strain }\end{cases}$

The Von Mises yield condition in the plastic mechanics is expressed as follows:

$\left(\sigma_{1}-\sigma_{2}\right)^{2}+\left(\sigma_{2}-\sigma_{3}\right)^{2}+\left(\sigma_{3}-\sigma_{1}\right)^{2}=2 \sigma_{y s}^{2}$

The $r$ is treated as equal to $r_{p}$ in Eq. (8), and the $r$ is substituted in the above equation, so the size of the plastic zone can be shown as follows:

$r_{p}=\frac{1}{2 \pi}\left(\frac{K_{I}}{\sigma_{y s}}\right)^{2}$ Plane stress

$r_{p}=\frac{1}{2 \pi}\left(\frac{K_{I}}{\sigma_{y s}}\right)^{2}(1-2 v)^{2}$ Plane strain

where $\sigma_{y s}$ is the yield stress, and $v$ is the poisson's ratio.

In Irwin's study, the size of the plastic zone was corrected:

$R=2 r_{p}=\frac{1}{\alpha \pi}\left(\frac{K_{I}}{\sigma_{y s}}\right)^{2}= \begin{cases}1 & \text { Plane stress } \\ 2 \sqrt{2} & \text { Plane strain }\end{cases}$

Considering the yielding of the crack tip, $a+r_{p}$ is used to replace the original crack length according to the Irwin's plasticity correction:

$K_{I}=\frac{1.1 \sigma \sqrt{\pi\left(a+r_{p}\right)}}{E(k)}$

After obtaining the stress intensity factor, the curve of $\mathrm{d} a / \mathrm{d} N \sim \Delta K$ can be created to predict the crack propagation life by combining with the results of the crack propagation experiment.

\subsection{The Finite Element Analysis of the Thermal Stress}

According to the thermal fatigue crack initiation and propagation experiments, the relationship between the crack initiation life, the crack propagation rate and the crack length can be obtained. However, the stress field strength near the crack tip in the thermal cycle cannot be monitored and obtained during the experiments, which need to be solved by the finite element analysis.

\subsubsection{The Calculation Method of the Strain Life Curve at the Crack Initiation Stage}

By means of the finite element analysis software, the command flow of the boundary condition of the circular temperature field was programmed, and the stress-strain response of the incision of the thermal fatigue sample was 
calculated by the elastic-plastic thermal stress calculation method [8-9].

The cycles of the thermal crack generation of the samples are different with different thicknesses and incision radiuses in the same temperature cycle. Also, the strain-life curve with the cycling temperature $\left(\Delta \varepsilon_{T} / 2-2 N_{f}\right)$ can be obtained by considering all available samples, and the calculation process is shown as Fig. 1.

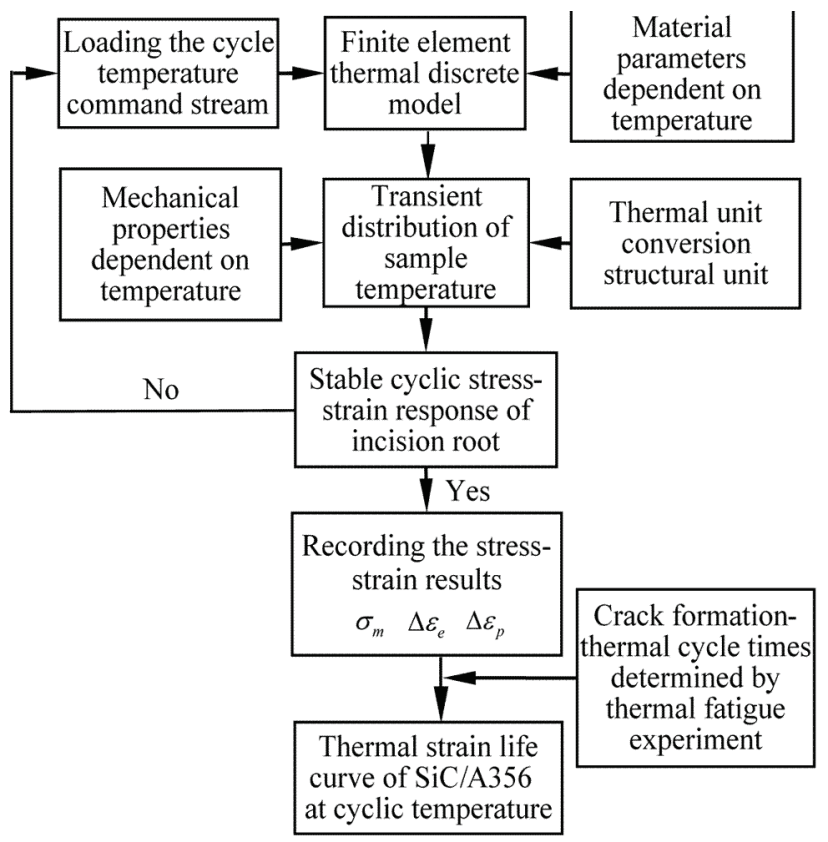

Figure 1 The flow chart of the strain life curve determined by FEM

\subsubsection{The Calculation Method of the Curve of the Crack Propagation Rate during the Process of the Thermal Crack Propagation}

According to the singular element method of the finite element, the crack opening displacement $\left(v\left(r_{1 / 4}, \pi\right)\right)$ at a quarter of node of the crack tip is substituted in Eq. (12) to obtain the stress intensity factor after obtaining the stressstrain solution of the crack tip.

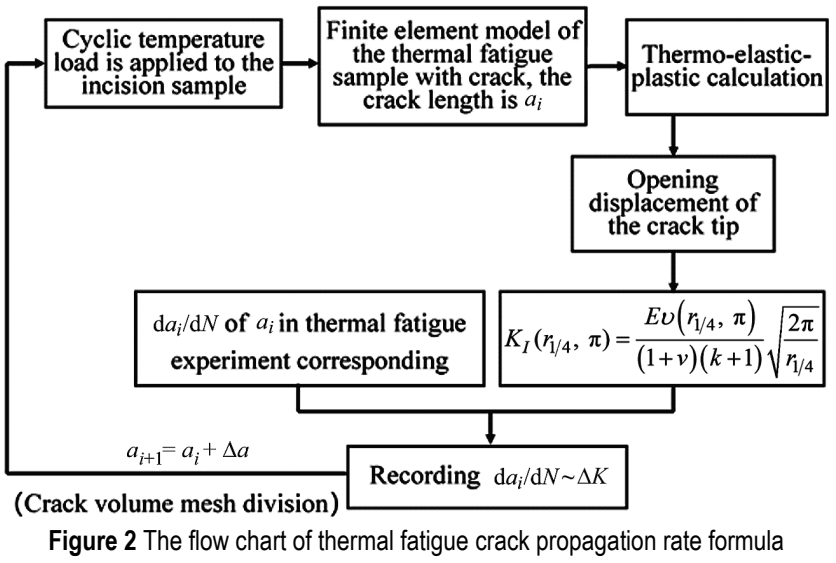

The solution of the stress intensity factor is obtained by using the thermo-elastic-plastic finite element method to simulate the thermal fatigue experiment process. Additionally, the corresponding points of range of the stress intensity factor $\left(\Delta K_{i}\right)$ and the crack propagation rate $\left(\mathrm{d} a_{i} / \mathrm{d} N\right)$ are obtained by means of the results of the thermal fatigue crack propagation experiment and the crack length. Thus, the function between the crack propagation rate and the stress intensity factor near the crack tip is established to predict the crack propagation life. The detailed process of the finite element simulation is shown as Fig. 2.

$K_{I}\left(r_{1 / 4}, \pi\right)=\frac{E v\left(r_{1 / 4}, \pi\right)}{(1+v)(k+1)} \sqrt{\frac{2 \pi}{r_{1 / 4}}}$

$\begin{cases}k=\frac{3-v}{1+v} & \text { (Plane stress state) } \\ k=3-4 v & \text { (Plane strain state) }\end{cases}$

\section{THE BASIC EXPERIMENT}

The $\mathrm{SiCp} / \mathrm{A} 356$ composite is produced by the liquid mixing method [10], the base material is the aluminium alloy A356, which is typical in industries. Meanwhile, the $\mathrm{SiC}$ particles have the hexagonal shape with a volume fraction of $20 \%$ in the composite.

\subsection{The Monotonic Tensile Experiment and the Monotonic Tensile Experiment of Brake Disc Material at Different Temperatures}

The monotonic tensile experiment and the monotonic tensile experiment are conducted by using the rod sample at the room temperature and the high temperature, and the experimental equipment is the material testing machine of MTS-Sintech65/G. The strain amplitude control with the absolute error less than $0.03 \%$ is used, and each experimental value is the average value of 3 to 5 effective values. The high-temperature experiment is conducted by using the high-temperature environmental box and the thermostat, and the experimental temperatures are $25{ }^{\circ} \mathrm{C}$, $150{ }^{\circ} \mathrm{C}, 300{ }^{\circ} \mathrm{C}$ and $450{ }^{\circ} \mathrm{C}$, respectively.

The Ramberg-Osgood $(R-O)$ constitutive model is used to fit the monotonic tensile experimental data according to the least squares method. Moreover, the average elastic modulus $E$, the yield strength $\sigma_{S}$, the tensile strength $\sigma_{b}$ and the parameters of the monotonic $R-O$ model of $\mathrm{SiCp} / \mathrm{A} 356$ composite at the room temperature and the high temperature are obtained, which are shown in Tab. 1. The $R-O$ cyclic constitutive model is used to fit the cyclic stress-strain test data according to the least squares method. Also, the parameters $(\dot{\varepsilon}=0.4 \% / s)$ of the $R-O$ model of $\mathrm{SiCp} / \mathrm{A} 356$ composite in the room-temperature and high-temperature cycles are obtained, as shown in Tab. 2.

Table 1 The monotonic properties of SiCp/A356 composite

\begin{tabular}{|c|c|c|c|c|c|c|}
\hline$T /{ }^{\circ} \mathrm{C}$ & $E / \mathrm{GPa}$ & $\sigma_{0.2} / \mathrm{MPa}$ & $\sigma_{b} / \mathrm{MPa}$ & $n$ & $K$ & $r$ \\
\hline 20 & 105 & 265 & 302 & 0,2365 & 1084 & 0,991 \\
\hline 150 & 90,4 & 209 & 225 & 0,2402 & 872 & 0,977 \\
\hline 300 & 82,5 & 133 & 118 & 0,1288 & 247 & 0,992 \\
\hline 450 & 49,9 & 55,5 & 34,4 & 0,0844 & 38 & 0,982 \\
\hline
\end{tabular}

Table 2 The fitted values of the cyclic $R$-O constitutive model of SiCp/A356

\begin{tabular}{|c|c|c|c|c|}
\hline$T /{ }^{\circ} \mathrm{C}$ & 20 & 150 & 200 & 300 \\
\hline$n^{\prime}$ & 0,1823 & 0,1748 & 0,1592 & 0,0662 \\
\hline$K^{\prime}$ & 916,4 & 644,8 & 465,7 & 109,9 \\
\hline$r$ & 0,991 & 0,981 & 0,968 & 0,989 \\
\hline
\end{tabular}




\subsection{The Thermal Fatigue Experiment of SiCp/A356 Composite}

As proposed in literature [11], the thermal fatigue experiment of $\mathrm{SiCp} / \mathrm{A} 356$ composite was carried out. The sample with the size of $50 \times 20 \times D \mathrm{~mm}$ was chosen for the experiment, and the thickness $(D)$ included $3 \mathrm{~mm}, 9 \mathrm{~mm}$, and $15 \mathrm{~mm}$. Also, the depth of the V-shaped incision was 2 $\mathrm{mm}$, and the radiuses $(R)$ of it included $0.1 \mathrm{~mm}, 0.15 \mathrm{~mm}$, and $0.20 \mathrm{~mm}$, as shown in Fig. 3 .

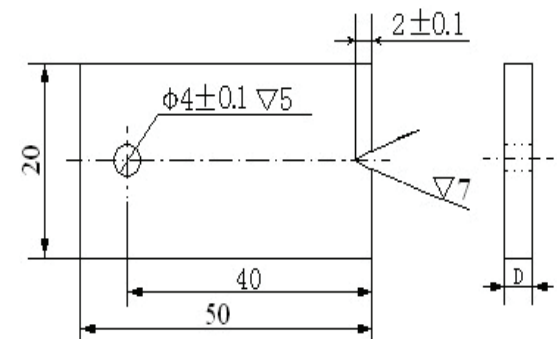

Figure 3 The shape and size of the thermal fatigue sample

According to the three groups of the sample thickness, there are three samples with the same incision radiuses in each group, which is helpful to obtain the average value. A tubular furnace with the power of $2 \mathrm{~kW}$ is chosen for the cyclic heating equipment, and the fluctuation of the maximum temperature is less than $\pm 3{ }^{\circ} \mathrm{C}$. Also, the circulating water is used for cooling. The range of the thermal cycling temperature is between $20{ }^{\circ} \mathrm{C}$ and $30{ }^{\circ} \mathrm{C}$, and the period of the thermal cycle is $145 \mathrm{~s} /$ cycle.

The length of the thermal fatigue crack is measured by a microscope of JQC $(15 \mathrm{~J})(\times 100)$ based on the surface direct reading method. The sample is cyclically heated and cooled in the thermal fatigue furnace after some time. Then, the sample incision is carefully observed by a microscope $(\times 100)$. Meanwhile, the time of the crack initiation cycle is calculated once the crack length (the average length) reaches $0.5 \mathrm{~mm}$, as shown in Tab. 3 .

After the fatigue crack generating, the thermal fatigue crack propagation test is continued. The crack length is recorded every 50 cycles, and the curve of the crack length with the cycle number is plotted, as shown in Fig. 4 . The crack growth rate is estimated to be $\mathrm{d} a / \mathrm{d} N=\Delta a / \Delta N$ after the experimental data further processed, thus the crack propagation rate and the crack length with different thicknesses show the following variation tendency in the double logarithmic coordinate system, as shown in Fig. 5.

Table 3 The mean cycle times of the samples with different thicknesses and incision radiuses after the crack length reaching $0.5 \mathrm{~mm}$ (the cyclic temperature: $20-300{ }^{\circ} \mathrm{C}$ )

\begin{tabular}{|c|c|c|c|c|c|c|c|c|}
\hline $\begin{array}{l}\text { Thickness } \\
D / \mathrm{mm}\end{array}$ & $\begin{array}{c}\text { Incision radius } \\
R / \mathrm{mm}\end{array}$ & $\begin{array}{l}\text { Cycle } \\
\text { time }\end{array}$ & $\begin{array}{c}\text { Thickness } \\
D / \mathrm{mm}\end{array}$ & $\begin{array}{c}\text { Incision radius } \\
R / \mathrm{mm}\end{array}$ & $\begin{array}{l}\text { Cycle } \\
\text { time }\end{array}$ & $\begin{array}{c}\text { Thickness } \\
D / \mathrm{mm}\end{array}$ & $\begin{array}{c}\text { Incision radius } \\
R / \mathrm{mm}\end{array}$ & $\begin{array}{l}\text { Cycle } \\
\text { time }\end{array}$ \\
\hline \multirow{3}{*}{15} & 0,10 & 300 & \multirow{3}{*}{9} & 0,10 & 280 & \multirow{3}{*}{3} & 0,10 & 250 \\
\hline & 0,15 & 350 & & 0,15 & 340 & & 0,15 & 310 \\
\hline & 0,20 & 450 & & 0,20 & 410 & & 0,20 & 360 \\
\hline
\end{tabular}

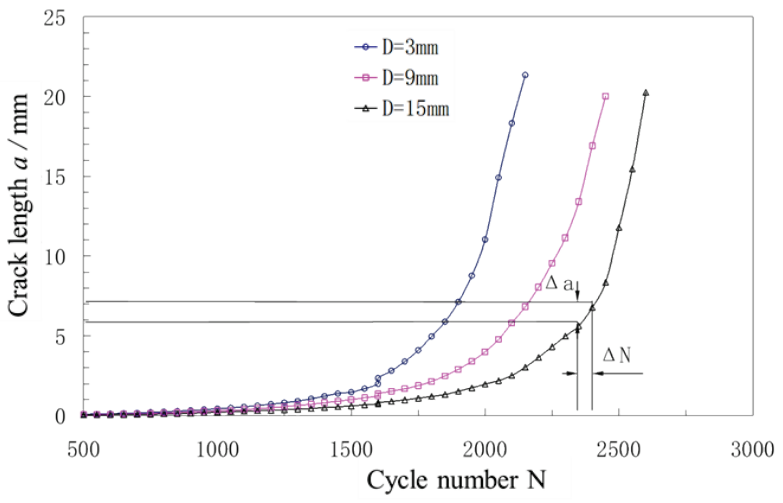

Figure 4 The relationship of the crack length with the cycle number for the samples with different thicknesses

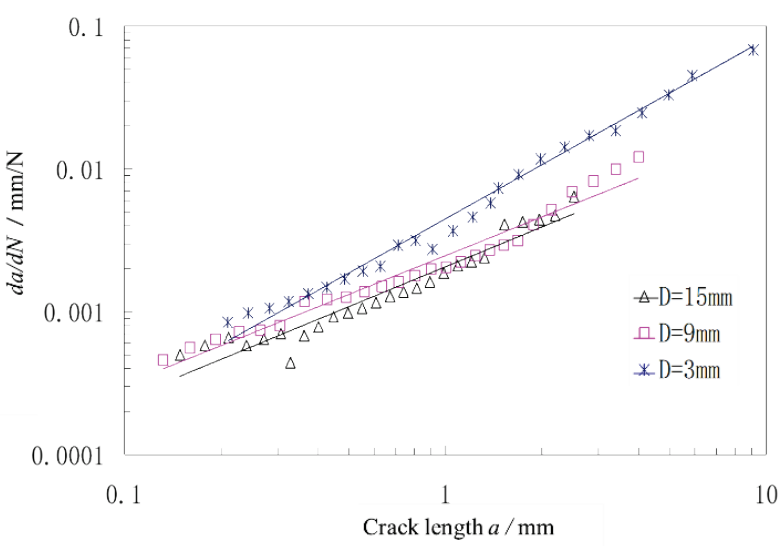

Figure $\mathbf{5}$ The relationship of the crack propagation rate and the crack length

\section{THE FINITE ELEMENT ANALYSIS OF THE THERMAL FATIGUE PROPERTIES OF THE BRAKE DISC \\ 4.1 The Curve of the Crack Initiation Life 4.1.1 The Stress-Strain Response of the Incision Sample}

The stress-strain response of the incision sample without crack is calculated based on the elastic-plastic finite element model. The applied thermal fatigue load is the same as that in the thermal fatigue experiment. The loading method of nonlinear transient calculation is a function table, and the cycle numbers depend on whether the stress-strain response reaching is stable. As for the stress field calculation, the self-restrained form is used to obtain the thermal stress-strain response caused by the variation of temperature, and the stress-strain results contain the effect of temperature.

Table 4 The strain amplitude determined by the finite element method

\begin{tabular}{|c|c|c|c|c|}
\hline $\begin{array}{c}\text { Cycle } \\
\text { time } \\
2 N_{f}\end{array}$ & $\begin{array}{c}\text { Total strain } \\
\text { amplitude } \\
\Delta \varepsilon_{T} / 2 / \%\end{array}$ & $\begin{array}{c}\text { Plastic strain } \\
\text { amplitude } \\
\Delta \varepsilon_{T p} / 2 / \%\end{array}$ & $\begin{array}{c}\text { Elastic strain } \\
\text { amplitude } \\
\Delta \varepsilon_{T e} / 2 / \%\end{array}$ & $\begin{array}{c}\text { Average } \\
\text { stress } \\
\sigma_{m} / \mathrm{MPa}\end{array}$ \\
\hline 1600 & 0,145 & 0,091 & 0,054 & -115 \\
\hline 900 & 0,174 & 0,111 & 0,064 & -110 \\
\hline 800 & 0,182 & 0,117 & 0,066 & $-102,5$ \\
\hline 720 & 0,190 & 0,123 & 0,068 & $-96,8$ \\
\hline 600 & 0,194 & 0,123 & 0,071 & $-86,5$ \\
\hline 560 & 0,199 & 0,127 & 0,073 & $-77,3$ \\
\hline 500 & 0,209 & 0,135 & 0,075 & -75 \\
\hline 400 & 0,251 & 0,171 & 0,080 & -65 \\
\hline 200 & 0,332 & 0,225 & 0,107 & -42 \\
\hline
\end{tabular}


During the thermal fatigue experiment, the load perpendicular to the direction of the incision is the main driving force of the crack initiation and propagation, so the thermal stress-strain response perpendicular to the direction of the incision is extracted. The strain amplitudes with different thermal cycle times are calculated, as shown in Tab. 4.

\subsubsection{The Curve of the Elastic Strain Life}

The finite element method is used to simulate the thermal strain stress response. The result shows that the stress cycle in the thermal fatigue experiment has the characteristics of the non-equal amplitude, and the average stress is less than zero. The fatigue strength factor of the life equation controlled by the elastic strain cannot be directly fitted. Moreover, the average stress can be converted into the strain life relationship with $R=-1$ according to the Goodman linear relationship [12] under the condition of the equivalent life. The Goodman line can be expressed as:

$$
\left(\sigma_{a} / \sigma_{-1, N}\right)+\left(\sigma_{m} / \sigma_{b}\right)=1
$$

where $\sigma_{a}$ is the cyclic stress amplitude at a given life; $\sigma_{-1, N}$ is the fatigue strength at a given cycle number $(R=$ $-1) ; \sigma_{b}$ is the tensile strength.

As the elastic part meets the Hooke law, so $\sigma_{a}=E \cdot \Delta \varepsilon_{e} / 2$. The tensile strength and the elastic modulus are determined according to Tab. 1, which are substituted in Eq. (14) to confirm the equal-amplitude fatigue strength $\left(\sigma_{-1, N}\right)$ with different $\sigma_{m}$. Thus, the thermoelastic strain life curve can be determined under the equal amplitude cycle, as shown in Fig. 6.

The fatigue strength coefficient $\left(\sigma_{f}^{\prime}=280.5 \mathrm{MPa}\right)$ and the fatigue strength index $(b=-0.2186)$ are fitted. Therefore, the curve of the elastic strain life with any mean stress state is expressed as Eq. (3):

$$
\frac{\Delta \varepsilon_{e}}{2}=\frac{280.5-\sigma_{m}}{E}\left(2 N_{e f}\right)^{-0.2186}
$$

Considering the effect of the average stress, the Eq. (15) can be used to estimate the life of the elastic strain control of the $\mathrm{SiCp} / \mathrm{A} 356$ composite under the cyclic stress-strain field.

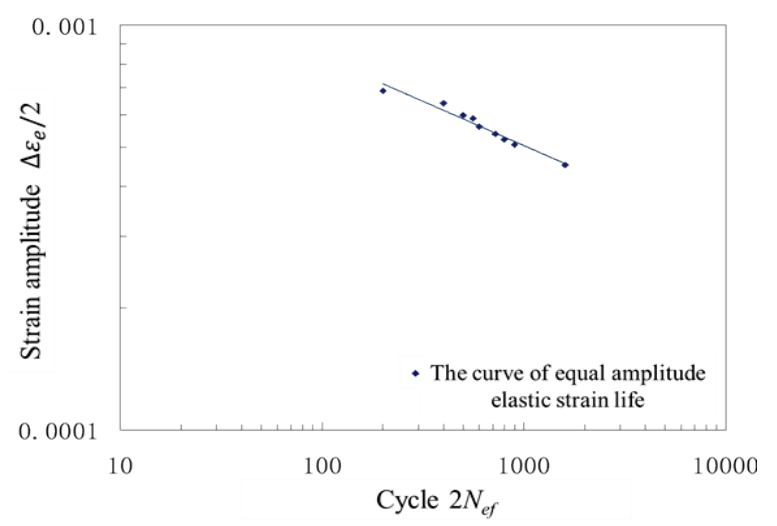

Figure 6 The curve of the equal-amplitude elastic strain life

\subsubsection{The Curve of the Plastic Strain Life}

The relationship between the plastic strain amplitude and the cycle times can be used to determine the curve of the plastic strain life controlled by the plastic strain, as shown in Fig. 7. The Eq. (4) is fitted as follows:

$$
\frac{\Delta \varepsilon_{p}}{2}=0.0376\left(2 N_{p f}\right)^{-0.5243}
$$

The above equation can be used to estimate the life of the $\mathrm{SiCp} / \mathrm{A} 356$ composite controlled by the range of the plastic strain range.

According to Eq. (5), Eq. (15) and Eq. (16), the initiation life of the thermal fatigue crack of disc surface can be evaluated, as shown in Fig.8.

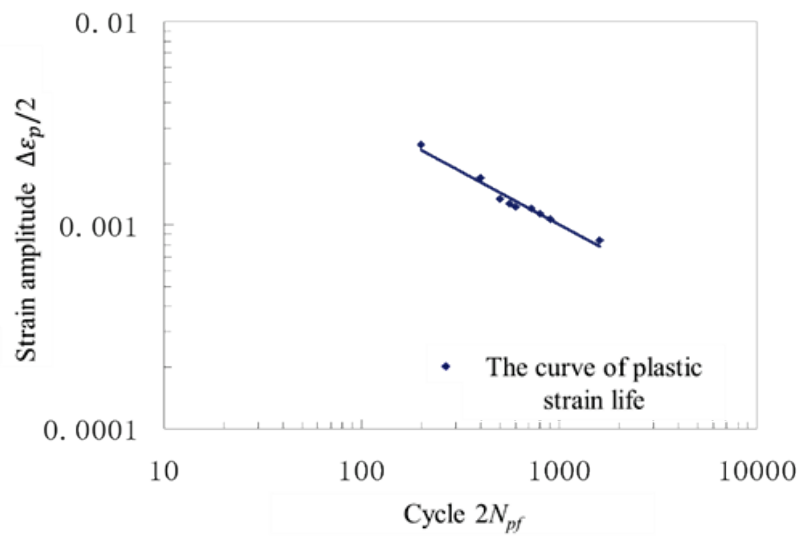

Figure 7 The curve of plastic strain life

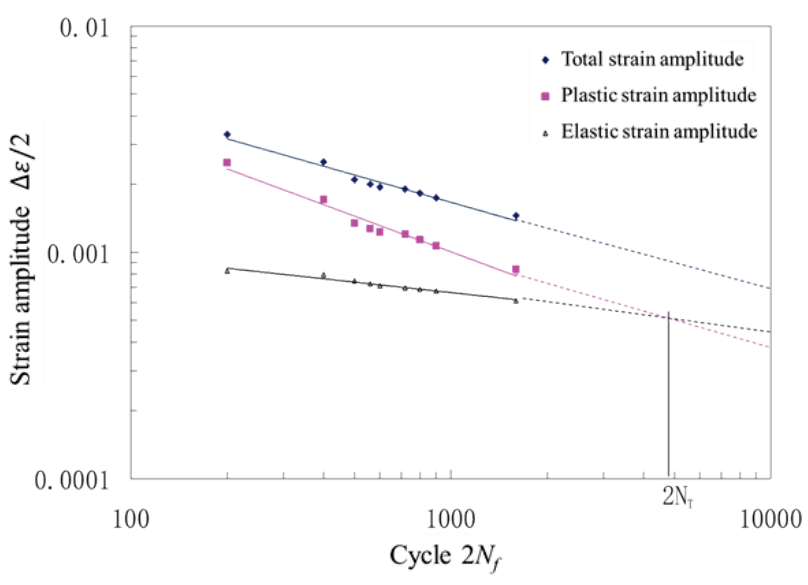

Figure 8 The curve of the thermal strain life

\section{2 The Curve of the Crack Propagation Life 4.2.1 The Simulation of the Stress Intensity Factor of the Crack Tip of Incision Samples under Thermal Cyclic Load}

The thermo-elastic-plastic finite element method is used to simulate the process of the thermal fatigue experiment, and the solution of the stress intensity factor of the crack tip is obtained. Also, the correlation between the crack growth rate and the stress intensity factor near the crack tip is established by combining the experimental results of the thermal fatigue crack propagation.

In the ANSYS software, the hexahedral with 8 nodes and the SOLID95 unit with 20 nodes are used to mesh the 
thermal fatigue sample, as shown in Fig. 9. The mechanical and thermo-physical parameters of the material with the temperature and the harden ability of the material are considered. Also, the curve of the temperature cycle is chosen as the boundary condition for the calculation of the temperature field on the external solid surface. The results of the temperature field as the boundary condition are applied to the analysis of the thermo-elastic-plastic stressstrain.

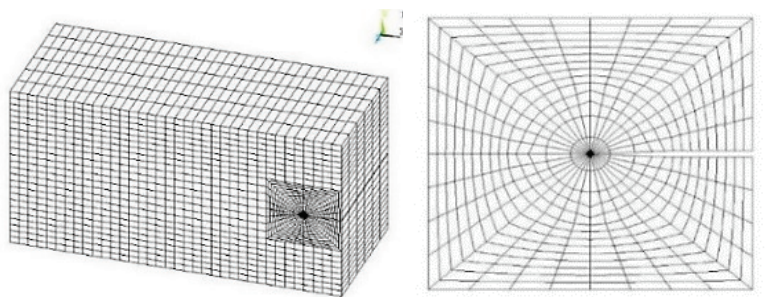

(a) The overall discrete sample (b) The local enlargement near the crack tip Figure 9 The finite element discrete of the thermal fatigue sample

The stress distributions of the crack tip at the room temperature $\left(20^{\circ} \mathrm{C}\right)$ and high temperature $\left(300{ }^{\circ} \mathrm{C}\right)$ are shown in Fig. 10. As shown in Fig. 10, the compressive stress near the crack tip at high temperature reaches -213 $\mathrm{MPa}$, which exceeds the limit of the compression yield at $300^{\circ} \mathrm{C}$ and the non-recoverable compression deformation appears. As the temperature rapidly decreases, the sample shrinks and the tensile stress is formed at the crack tip in order to balance the deformation caused by the shrinkage. The tensile stress reaches the maximum value as the sample temperature completely reduces to the room temperature. Moreover, the reciprocating cycle of tension and compression forms the dynamic force of the fatigue crack propagation.

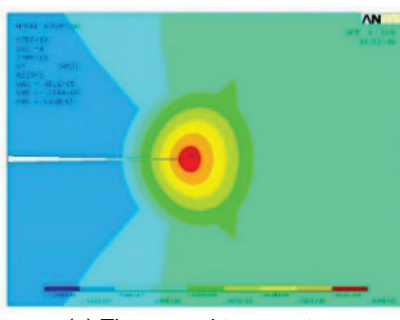

(a) The normal temperatures

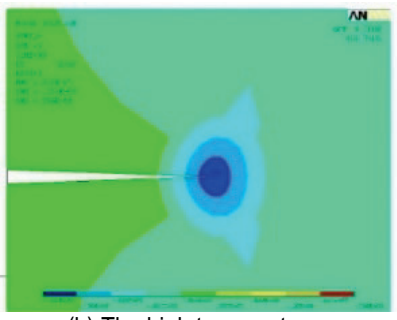

(b) The high temperatures
Figure 10 The vertical stress distribution of the crack tip under normal and high temperatures

The size of the plastic zone is shown as Fig. 11. $r_{p}=$ $0.036 \mathrm{~mm}, a=2 \mathrm{~mm}$, and $a / r_{p}=55.56>20$, which meets the small-scale yield criteria. It can be speculated that the crack tip is in the small-scale yield state in the experimental range, so the stress-strain field of the crack tip can be evaluated by the range of linear elastic fracture parametercrack tip stress intensity factor. The stress-strain response with the temperature at a quarter node of the crack tip is shown in Fig. 12.

The stress intensity factor near the crack tip of the thermal fatigue sample under the cyclic thermal stress is $\Delta K_{I}=K_{I \text { max }}-K_{I \text { min }}$. As suggested by the linear elastic fracture mechanics, the compressive stress does not contribute to the crack propagation [13]. Therefore, the $K_{I \text { min }}$ is equal to 0 for the maximum temperature, and the curve of $\mathrm{d} a / \mathrm{d} N \sim \Delta K$ is that of $R=0$. As the temperature decreases to the room temperature, the residual stress acts on the location near the crack tip. Also, the opening displacement of a quarter of node of the crack tip is substituted in Eq. (13), and $K_{\text {I } \max }$ is obtained. The range of the stress intensity factor corresponding to the crack length is $\Delta K_{I}=K_{I \max }$.

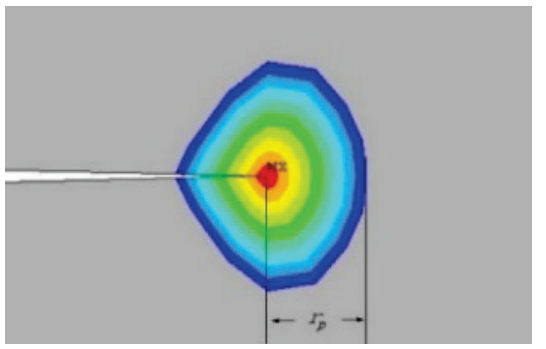

Figure 11 Crack tip plastic dimension

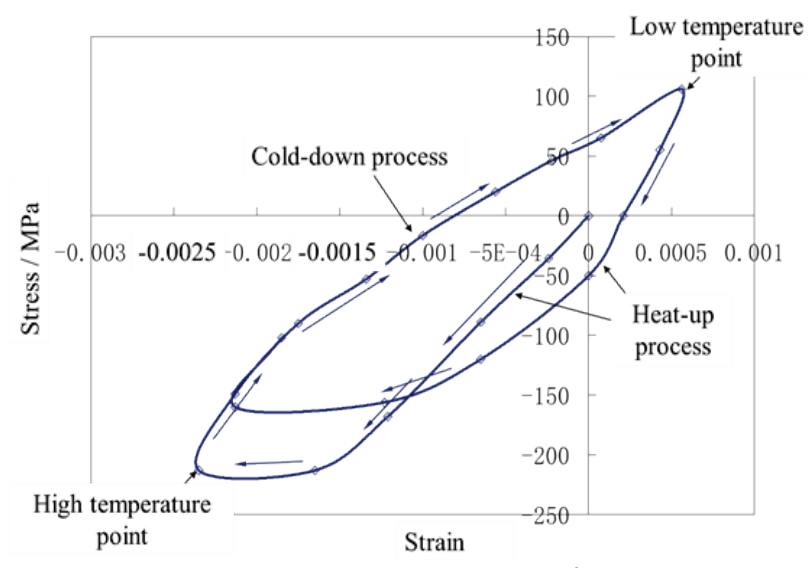

Figure 12 The steady stress-strain loop of crack tip

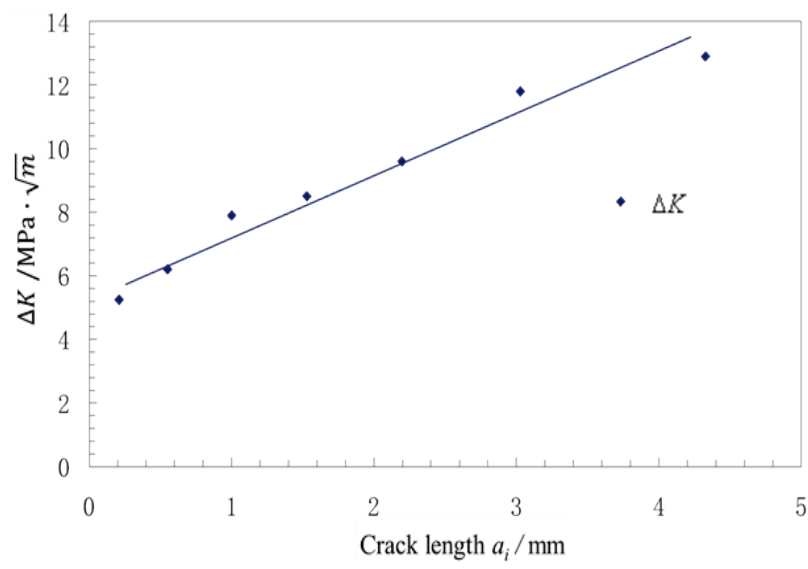

Figure 13 Relationship of $\Delta K$ and $a_{i}$

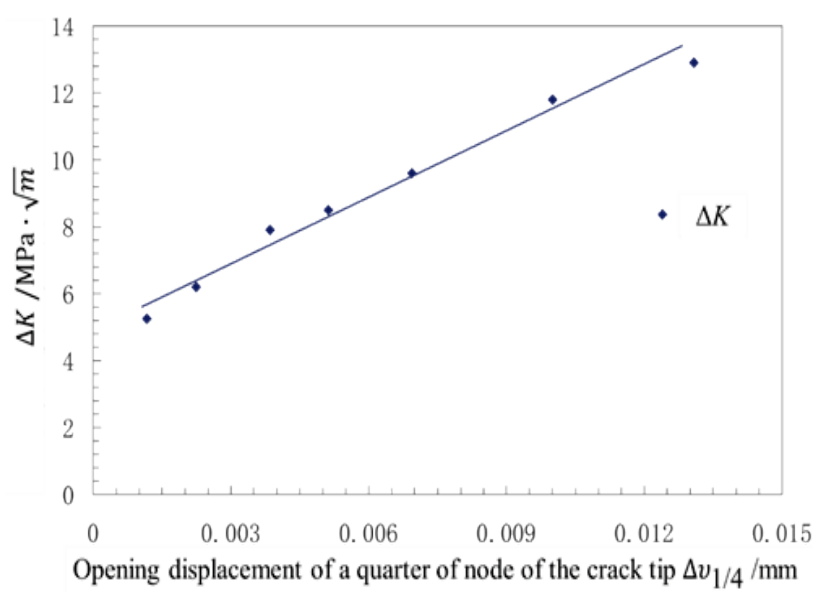

Figure 14 Relationship of $\Delta K$ and $v_{1 / 4}$ 
According to the results of the thermal fatigue experiment, seven crack lengths $a_{i}(i=1,2, \ldots, 9)$ are chosen to calculate the cyclic thermal stress and strain, and the corresponding range of the stress intensity factor range $\Delta K_{i}(i=1,2, \ldots, 9)$ can be obtained. The relationships between $\Delta K$, the crack length and the opening displacement of a quarter of node of the crack tip are shown as Fig. 13 and Fig. 14, respectively. It can be seen that $\Delta K$ increases with the crack propagation, and the crack will expand unsteadily once the $K_{I}$ reaches the fracture toughness $\left(K_{I c}\right)$.

\subsubsection{The Determination of the Parameters of the Crack Propagation Curve}

The crack propagation rate $\left(\mathrm{d} a_{i} / \mathrm{d} N\right)$ obtained by the experiment and the range of the stress intensity factor $\left(\Delta K_{i}\right)$ determined by the finite element method are used to obtain the corresponding points, which approximately form a line in the logarithmic coordinate, as shown in Fig. 15. The curve shown in Fig. 15 is close to the crack propagation law of $\mathrm{SiCp} / \mathrm{A} 356$ composite at the room temperature because of the maximum stress intensity factor appearing at the room temperature.

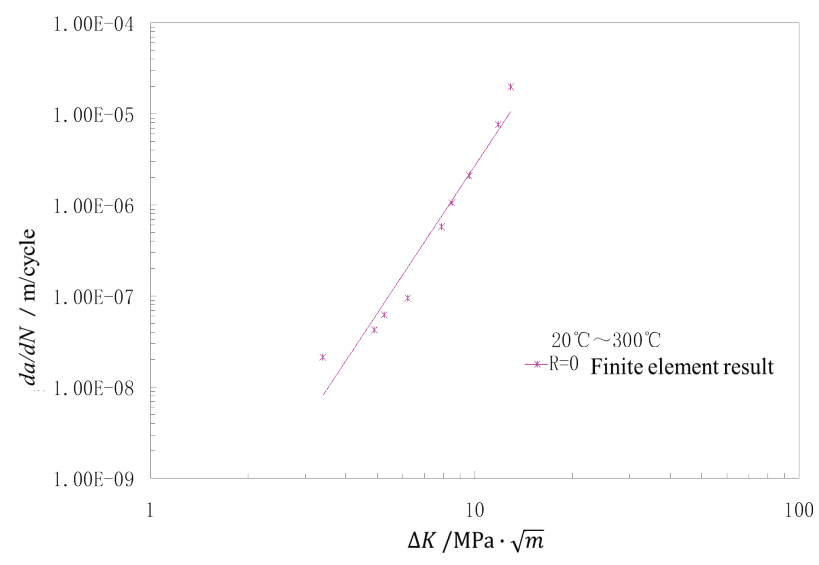

Figure 15 The $\mathrm{d} a / \mathrm{d} N \sim \Delta K$ curve of $\mathrm{SiCp} / \mathrm{A} 356$ composite fitted by the finite element method

In 1989, Shang [14] showed the results of the fatigue crack propagation experiment of the $20 \% \quad \mathrm{SiCp} / \mathrm{Al}$ composite with the stress ratio $(R=0.1)$ at the room temperature after the T6 heat treatment. Also, the material properties proposed in this study and in the above literature are listed in Tab. 5.

Table 5 The comparison between the properties proposed in this study and the literature [15]

\begin{tabular}{|c|c|c|c|c|c|}
\hline \multirow{2}{*}{ Material } & \multicolumn{5}{|c|}{ Properties } \\
\cline { 2 - 6 } & $\begin{array}{c}\text { Elastic modulus } \\
E / \mathrm{MPa}\end{array}$ & $\begin{array}{c}\text { Yield stress } \\
\sigma_{y} / \mathrm{MPa}\end{array}$ & $\begin{array}{c}\text { Tensile strength } \\
\sigma_{b} / \mathrm{MPa}\end{array}$ & $\begin{array}{c}\text { Fracture toughness } \\
K_{I c} / \mathrm{MPa} \cdot \sqrt{m}\end{array}$ & $\begin{array}{c}\text { Threshold } \\
\Delta K_{t h} / \mathrm{MPa} \cdot \sqrt{m}\end{array}$ \\
\hline $20 \% \mathrm{SiCp} / \mathrm{A} 356$ & 105 & 265 & 302 & 14,5 & - \\
\hline $20 \% \mathrm{SiCp} / \mathrm{Al}$ & 94,1 & 400 & 470 & 14,0 & 2,6 \\
\hline
\end{tabular}

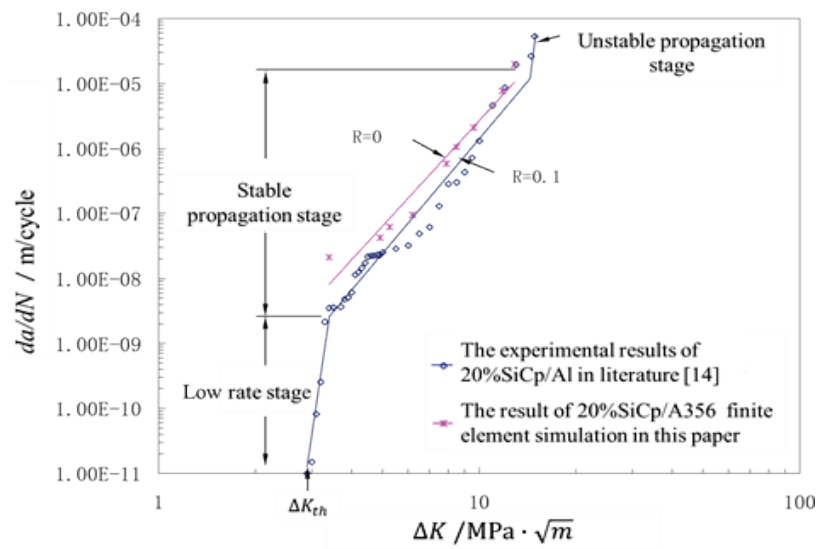

Figure 16 The comparison of the crack propagation rate curve

As shown in Tab. 5, the differences of the tensile strength and the yield between the two materials are large, but the difference of the fracture toughness is mild. The fatigue crack propagation curve $(\mathrm{d} a / \mathrm{d} N \sim \Delta K)$ proposed in this study is shown in Fig. 16. It can be seen that the crack propagation curve of the $20 \% \mathrm{SiCp} / \mathrm{Al}$ proposed by Shang [14] covers the three stages of the fatigue crack propagation, including the low rate stage near the threshold $(\Delta K=2.6 \mathrm{MPa} \cdot \sqrt{m})$, the stable propagation stage, unstable propagation stage. As shown in Fig. 16, the curve of the crack propagation rate proposed in this paper is in the second stage of the crack propagation, namely the stable propagation phase, which is close to the result proposed in Ref. [15]. As shown in Fig. 16, it can be speculated that the curve of the crack propagation rate fitted by the finite element method is in accordance with the law of the crack propagation of the particle reinforced aluminium matrix composite. However, the accuracy needs to be verified by the direct experiment, which is unpractical due to the technology of the current thermal fatigue experiment.

The fatigue crack propagation data proposed by Shang [14] are obtained by the fatigue crack propagation experiment at the room temperature. In this study, the curve of the thermal fatigue crack propagation rate obtained by the finite element method considers the temperature influence, so the result of this study is higher than that of Shang [14].

The Paris equation is used to fit the curve of the thermal fatigue crack propagation, as shown in Tab. 6.

Table 6 The equation of the crack propagation rate

\begin{tabular}{|c|c|}
\hline Material & $\begin{array}{c}\text { The equation of the crack propagation rate } \\
\frac{\mathrm{d} a}{\mathrm{~d} N}=C(\Delta K)^{m}\end{array}$ \\
\hline $\begin{array}{c}20 \% \mathrm{SiCp} / \mathrm{A} 356 \\
\text { (this study) }\end{array}$ & $\frac{\mathrm{d} a}{\mathrm{~d} N}=1.1156 \times 10^{-11}(\Delta K)^{5.3833}$ \\
\hline $\begin{array}{c}20 \% \mathrm{SiCp} / \mathrm{Al} \\
(\text { Shang }[14])\end{array}$ & $\frac{\mathrm{d} a}{\mathrm{~d} N}=2.0813 \times 10^{-12}(\Delta K)^{5.7844}$ \\
\hline
\end{tabular}

\section{CONCLUSION}

Based on the experiment, the monotonic properties and the parameters of the cyclic R-O constitutive model of $\mathrm{SiCp} / \mathrm{A} 356$ composite were obtained. Also, the relationship of the crack propagation rate and the crack length of $\mathrm{SiCp} / \mathrm{A} 356$ was gained.

The fatigue life of brake disc is divided into two parts: the crack initiation life and the crack propagation life. On one hand, the evaluation criterion of the total strain life is established. On the other hand, the stress intensity factor of the crack tip is calculated by the method of a quarter node 
displacement of the singular unit, and the curve of the thermal fatigue crack propagation of the SiCp / A356 composite $(\mathrm{d} a / \mathrm{d} N \sim \Delta K)$ is established based on the relationship between the crack propagation rate and the crack length in the thermal fatigue experiment, which provide the necessary condition for the evaluation of the initiation and propagation lives of the thermal fatigue crack of the brake disc of SiCp/A356 composite. Finally, the total thermal fatigue life of brake disc of $\mathrm{SiCp} / \mathrm{A} 356$ composite is obtained.

\section{Acknowledgement}

The authors are sincerely grateful for the financial support of the Project of Ministry of Science and Technology (2017YFB11201300).

\section{REFERENCES}

[1] Manson, S. S. (1953). Behavior of materials under conditions of thermal stress. NACA, TN2933.

[2] Li, Z. Q., Han, J. M., Li, W. J., \& Pan, L. L. (2014). Low cycle fatigue behavior of $\mathrm{Cr}-\mathrm{Mo}-\mathrm{V}$ low alloy steel used for railway brake discs. Materials and Design, 56(4), 146-157. https://doi.org/10.1016/j.matdes.2013.10.093

[3] Zhou, S. X., Yang, Y., \& Xie, J. L. (2011). Analysis of transient temperature and thermal stress distribution on the high-speed strain brake disk by simulation. Journal of Mechanical Engineering, 47(22), 126-131. https://doi.org/10.3901/JME.2011.22.126

[4] Wu, S. C., Zhang, S. Q., \& Xu, Z. W. (2016). Thermal crack growth-based fatigue life prediction due to braking for a highspeed railway brake disc. International Journal of Fatigue, 87, 359-369. https://doi.org/10.1016/j.ijfatigue.2016.02.024

[5] Science and Technology Committee of the Ministry of Aviation Industry. (1987). Handbook of strain fatigue analysis. Bei Jing, BJ : Science Press.

[6] Gao, Q. (1986). Engineering fracture mechanics. Chong Qing, CQ: Chongqing University Press.

[7] Cheng, J. \& Zhao, S. S. (2006). Fracture mechanics. Bei Jing, BJ: Science Press.

[8] Shuuji, T. (1984). Thermal stress and thermal fatigue (Basic theory and design application). Translate by Guo, Y. W. Bei Jing, BJ : National Defence Industry Press.

[9] Xie, Y. Q. \& He, F. B. (1982). Finite element method in elasticity and plasticity mechanics. Bei Jing, BJ: Mechanical Industry Press.

[10] Han, J. M. (2004). Study on SiCp/A356 brake disc materials used in coupling service condition with strong friction and thermal stress. Doctoral dissertation of Beijing Jiaotong University.

[11] Zhang, J. Q., Zhou, S. X., Yang, Y., \& Xie, J. L. (2011). Research on the thermal fatigue behaviors of the composites material SiCp/A356 used on the high-speed train. Engineering Mechanics, 28(8), 252-256.

[12] Chen, C. Y. (2002). Fatigue and fracture. Wu Han, HB: Huazhong University of Science \& Technology Press.

[13] Donzella, G., Scepi, M., Solazzi, L., \& Trombini, F. (1998). The effect of block braking on the residual stress state of a solid railway wheel. Proceedings of the Institution of Mechanical Engineers, Part F: Journal of Rail and Rapid Transit, 212(2), 145-158. https://doi.org/10.1243/0954409981530751

[14] Shang, J. (1989). Micro-mechanisms of fatigue crack propagation in particulate-reinforced metal matrix composites. Doctoral dissertation of University of California, Berkeley.
[15] Sadananda, K., Vasudevan, A. K., \& Kang, I. W. (2003). Effect of superimposed monotonic fracture modes on the $\Delta K$ and $K_{\max }$ parameters of fatigue crack propagation. Acta Materialia, 51(12), 3399-3414.

https://doi.org/10.1016/S1359-6454(03)00159-9

\section{Contact information:}

Guangxue YANG, Associate Professor

(Corresponding author)

School of Mechanical, Electronic and Control Engineering,

Beijing Jiaotong University,

No. 3 Shangyuancun, Haidian District, Beijing 100044, China

E-mail: gxyang@bjtu.edu.cn

Yue YANG, Vehicle Performance Manager

BAIC motor corporation LTD. R\&D center

NO. 99 Shuanghe street, Shunyi District, Beijing, 101300, China

E-mail: yangyue@baicmotor.com 